\title{
Testing and design of a passive container for the optimisation of highbush blueberries (Vaccinium corymbosum L.) cold chain
}

\author{
Roberto Beghi, Simone V. Marai, Valentina Giovenzana, Enrico Ferrari, \\ Riccardo Guidetti \\ Department of Agricultural and Environmental Sciences - Production, Landscape, Agroenergy,
University of Milano, Italy
}

\begin{abstract}
The aim of this work is to test a passive cooling system (PCS) on highbush blueberry (Vaccinium corymbosum L.) to verify cooling performances soon after harvest. Based on experimental results the cooling trend was modelled and a dedicated system was designed for the optimisation of blueberries cold chain.

The evolution of qualitative characteristics of stored fruits was evaluated analysing the percentage of damaged berries, the weight loss, the texture, the titratable acidity and the total soluble solids content.

The analysis of temperature profiles during transport using PCS shows how this device is not fast enough in tearing down the blueberries field heat. A computer simulation, using finite elements method modelling, considering the thermo-physical properties of materials used and the boundary conditions arising from experimental data collected was carried out. Computer modelling has provided the characteristics of geometry, thickness, type and density of the material to obtain the desired cooling performance.
\end{abstract}

Correspondence: Valentina Giovenzana, Department of Agricultural and Environmental Sciences - Production, Landscape, Agroenergy (DiSAA), University of Milano, via G. Celoria 2, 20133 Milano, Italy.

Tel.: +39.02.50316843.

E-mail: valentina.giovenzana@unimi.it

Key words: Blueberry; quality; heat transfer modelling; finite elements method; heat field removal.

Contributions: RB, SVM, VG, data collecting and analysing, manuscript writing; EF, RG, manuscript reviewing and work supervising.

Conflict of interests: the authors declare no potential conflict of interests.

Received for publication: 30 October 2015.

Accepted for publication: 4 March 2016.

(C) Copyright R. Beghi et al., 2016

Licensee PAGEPress, Italy

Journal of Agricultural Engineering 2016; XLVII:520

doi:10.4081/jae.2016.520

This article is distributed under the terms of the Creative Commons Attribution Noncommercial License (by-nc 4.0) which permits any noncommercial use, distribution, and reproduction in any medium, provided the original author(s) and source are credited.

\section{Introduction}

The international market has considerably increased by $35.5 \%$ from 2008 to 2010 the demand for fresh blueberries, reaching a production of about 230,700 tons/year (Brazelton, 2011). The main quality indicators for these berries are fruit appearance (colour, size, shape, and no blemishing), firmness, chemical compounds (soluble solids content, titratable acidity, and volatile compounds), and nutritive value (Sinelli et al., 2008), mainly vitamins A and C (Mitcham et al., 2012). Blueberries have a low ethylene production, from 0.1 to $1.0 \mathrm{~L} \mathrm{~kg}^{-1} \mathrm{~h}^{-1}$ at $5^{\circ} \mathrm{C}$ (Mitcham et al., 2012) and significantly high respiratory rate from 2 to $10 \mathrm{mg} \mathrm{CO}_{2} \mathrm{~kg}^{-1} \mathrm{~h}^{-1}$ at $0^{\circ} \mathrm{C}$ (Moggia, 1991), depending on the cultivar.

Fruit quality must be maintained during transportation to distant markets to guarantee the acceptability from consumers. Paniagua et al. (2014) studied the interaction of delays in cooling, temperature variation and atmosphere conditions on Brigitta quality. Blueberries should be stored at low temperature $\left(0^{\circ} \mathrm{C}\right)$ with a relative humidity between 90 and $95 \%$ to maintain its high quality up to 18 days (Cantwell, 2012). In fact, to reduce the time between picking and storage is particularly critical because fruits and vegetables transpire and respire at high rates at field temperatures. A rapid and uniform postharvest cooling is important to maintain the quality and enhance the shelf life of fresh horticultural products (Kader, 2002).

Precooling was first introduced by Ryall and Pentzer (1982) and since then was defined by Nowak and Mynett (1985) as the immediate lowering of commodity field heat following harvest. Janick (1986) defined it as the removal of field heat from freshly harvested produce in order to slow down metabolism and reduce deterioration prior to transport or storage. Rudnucki et al. (1991) simply defined precooling as the quick reduction in temperature of the product. Bartlett (1971) stated that rapid cooling is the key for a successful storage of vegetables and other horticultural crops. Baird and Gaffney (1976) considered precooling as the most important of all the operations used in the maintenance of produce freshness. Produce is usually cooled to its long-term storage temperature in special facilities designed to rapidly remove produce heat. Forced-air cooling is the most widely adaptable method and is used for many fruits, fruit-type vegetables, and cut flowers (Thompson et al., 2008). Although this postharvest cooling is routinely used in the industry by forcing cold air through individual packages of produce (especially in the case of highly perishable and delicate products, such as berries), significant losses still occur due to non-uniform cooling. Several studies have shown that the package system design has a major role in the efficiency of the process (Hoang et al., 2003; Castro et al., 2004). Commercial scale forced air cooling system currently used by the industry are still largely designed based on empirical techniques, and they remain deficient in promoting rapid and uniform cooling (Anderson et al., 2004). 
Others simple and low-cost cooling devices commonly used soon after harvest are based on a convective flow inside a container equipped with a passive refrigeration system consisting of ice in a sealed package, providing temperature control during transportation and handling.

Jackson et al. (1999) studied the quality of lowbush blueberries through the changing of 10 attributes testing different prepacking temperature, delay time and storage time. They concluded that to improve the shelf life of lowbush blueberries the reduction of the delay time is required and, in particular a quick cooling from the field temperature $\left(26^{\circ} \mathrm{C}\right)$ to $5^{\circ} \mathrm{C}$ reduces microbial activity, softening, and splitting, improving marketability and firmness.

Aim of this work is to test a commercial passive cooling system (PCS) on highbush blueberry (Vaccinium corymbosum L.) to verify cooling performance soon after harvest on this small fruit. Based on experimental results the cooling trend was modelled and a dedicated system was designed for the optimisation of blueberries cold chain.

\section{Materials and methods}

\section{The passive cooling system}

The studied cooling system is a commercial device currently used for the cooling soon after harvest of other small fruits (e.g., woodland strawberry, Fragaria vesca L.). The PCS (Figure 1) is composed of a polystyrene container with a thickness of $2 \mathrm{~cm}$ and a density of $25 \mathrm{~kg}$ $\mathrm{m}^{-3}$ equipped with a zone where a charge of melting ice is placed. Each hermetic charge is filled with 1.8 litre of water and placed in a freezer at $-20^{\circ} \mathrm{C}$ before use it. The harvested fruits were collected in 8 plastic boxes laid on the charge. The system subtracts the field heat from freshly harvested fruits during transport. Each pack $(42.5 \mathrm{~cm}$ length, $33.5 \mathrm{~cm}$ width and $12 \mathrm{~cm}$ height) is a closed system equipped with a polystyrene cover with a thickness of $2 \mathrm{~cm}$ and contains $2 \mathrm{~kg}$ of blueberries. The PCS can be used individually or stacked, generally up to a maximum of 5 piled elements.

\section{Blueberry samples}

Samples of highbush blueberry (Vaccinium corymbosum L.), Brigitta cultivar, were harvested in the Valtellina area (northern Italy) during
2012 from 4- to 5-years-old plants (berries were harvested at full ripe stage). Blueberries were collected weekly in three subsequent week (during July). Four kg of blueberries were harvested at each sampling date, for a total of $12 \mathrm{~kg}$.

\section{Sampling}

The PCS was used for the cooling soon after harvest during transportation of the blueberries from the field (Sondrio) to the storage cells of a hypothetic warehouse (Milano) corresponding to a distance of about $150 \mathrm{~km}$. The monitoring of the PCS internal conditions was carried out through the use of six temperature sensors and data-logger FT800 [Econorma S.a.s., S. Vendemiano (TV), Italy] for temperature measurement, positioned in three different points of the container (Figure 1B): two sensors were placed among fruits, two sensors positioned on the ice charge, and two under the ice slab. Data from each monitoring position were averaged before elaboration. Based on the temperature profile registered during transport, cooling performance was analysed.

At each sampling, $2 \mathrm{~kg}$ of the harvested fruits were placed in the 8 plastic boxes of $250 \mathrm{~g}$ used as repetitions inside PCS. Similarly, other 2 $\mathrm{kg}$, divided in 8 boxes of $250 \mathrm{~g}$, were transported in a traditional plastic case (control) for small fruits. Sampling were performed weekly for three weeks. All the fruits were subsequently placed in refrigerated storage room for two months (8-9 weeks) at the temperatures of $0^{\circ} \mathrm{C}$ and $90 \%$ relative humidity, separating the blueberries collected using PCS from the control samples.

The evolution of stored fruits qualitative characteristics was evaluated by periodic sampling (seven experimental points, Table 1), analysing the percentage of damaged berries, weight loss and texture. Moreover the main physical and chemical analyses were carried out.

\section{Physical and chemical analysis}

\section{Weight loss determination}

At each sampling date the blueberries collected using PCS and without PCS were weighed using a precision balance, range $500.00 \mathrm{~g} \pm 0.01$ (Gibertini Europe, Milano, Italy).

\section{Determination of edible berries percentage}

The percentage of healthy berries and unmarketable ones was eval-
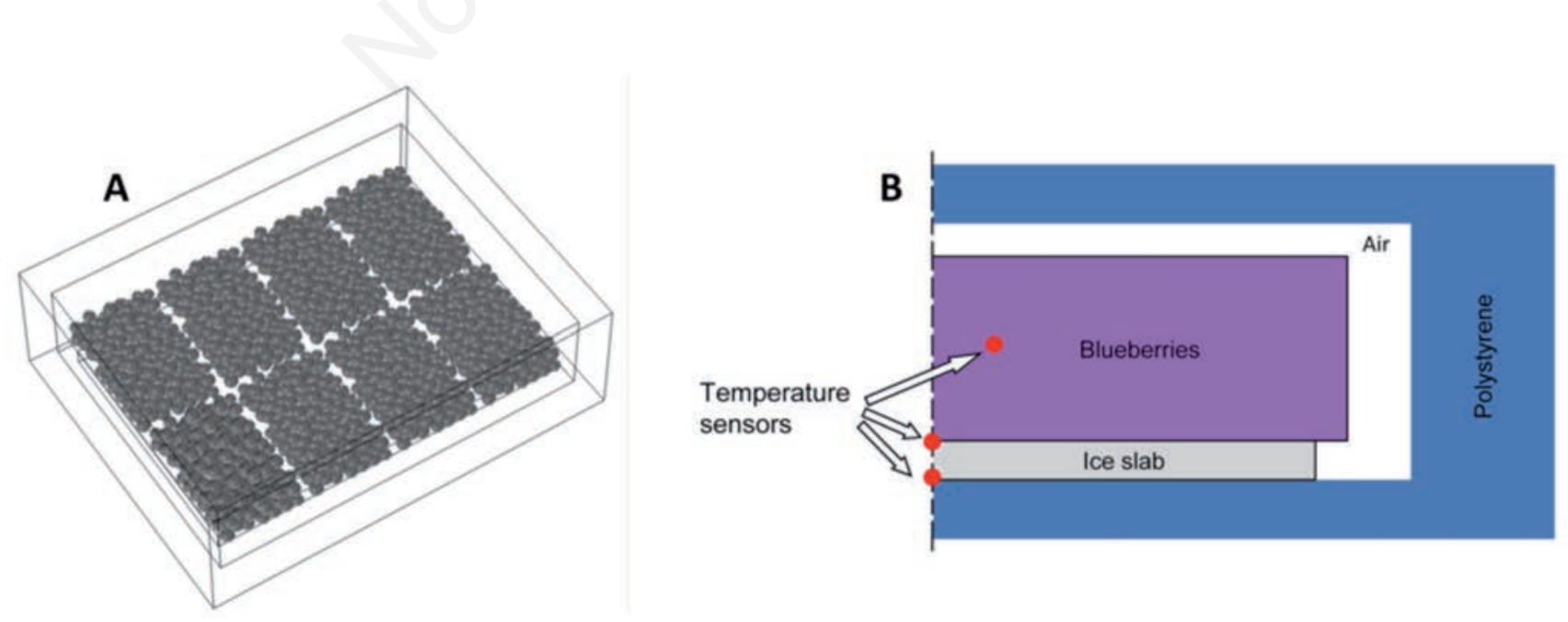

Figure 1. Structure of (A) passive cooling system (PCS) filled with blueberries, and (B) transversal view of the half vertical section of PCS with the position of the temperature sensors. 
uated at each sampling time. Unmarketable berries showed microbial growth and texture softening considered to be not compatible with the sale. The percentage of damaged berries was visually assessed by experts, removing all damaged berries from the healthy ones.

\section{Firmness determination}

Firmness of fruits was determined using a dynamometer [Instron Universal Testing Machine, Pianezza (T0), Italy], supported by the software BlueHill v2.0. The force-distance curve was acquired for each sample. Measurements were carried out on 10 berries at each sampling and for each experimental condition. Berries were analysed along the equator region. Average mass of a single berry was $2.0 \pm 0.2 \mathrm{~g}$. Operating conditions for the test were: i) load cell: full scale $10 \mathrm{~N}$; ii) probe: punch with a negligible diameter, if compared to sample size; iii) threshold load value of $0.5 \mathrm{~N}$; iv) test-speed of $20 \mathrm{~mm} / \mathrm{min}$; v) end test standard: sample penetration for $20 \mathrm{~mm}$.

Firmness parameters obtained from the elaboration of the force-distance curve were: i) peak force $(\mathrm{N})$ : the maximum force registered during penetration; ii) penetration energy $(\mathrm{mJ})$ : work required to penetrate fruit pulp from 5 to $18 \mathrm{~mm}$.

\section{Titratable acidity determination}

Fresh berries (200 g) were homogenised for 2 min, using a commercial blender (Waring Blender LB20E, Waring Products, New Hartford, CT, USA), filtered and immediately subjected to analysis. Five grams of blueberry homogenate were added to $30 \mathrm{~g}$ of distilled water. The samples were placed under agitation for $15 \mathrm{~min}$ and titratable acidity (meq $100 \mathrm{~g}^{-1}$ fresh weight) was measured using an automatic sample titrator (Titromatic 2S-3B, Crison, Barcelona, Spain).

\section{Total soluble solids determination}

Total soluble solids (TSS) were measured using a portable digital refractometer (model DBX-55, Atago, Tokyo, Japan). Few drops of the juice obtained from squeezing 30 berries were placed on the refractometer, previously calibrated with distilled water. Result was directly expressed in Brix degrees ( ${ }^{\circ}$ Brix).

\section{Statistical analysis}

Analysis of variance was performed in order to highlight significant differences among sampling times according to Duncan's test $(\mathrm{P}<0.05)$ (SPSS 19.0 for Windows). Moreover, significant differences between blueberries transported with or without PCS, for each sampling date, were computed using Student's $t$ test (SPSS 19.0 for Windows).

\section{Modelling}

The simulation was performed with commercial finite element software: COMSOL Multiphysics version 3.5a (COMSOL, Stockholm, Sweden) and its Heat transfer module.

Considering the heat transfer phenomena between the blueberries harvested, the ambient surrounding the box and the melting ice slab, a mathematical model based on heat transfer in continuous media is used to model the cooling of blueberries. Considering the need to determine an end time for the simulation, some preliminary tests were performed (date not shown) to define the time necessary for the complete melting of the ice slab. Based on these preliminary results, an arbitrary time of $15 \mathrm{~h}$ for the simulation ending was fixed. The governing Equation (1) and the corresponding boundary condition (2) will refer to a heat balance equation. The convection heat transfer inside the PCS was neglected because of the little dimension of the free space for the airflow, furthermore the refrigerant slab was at the bottom of the box and there was a deposition of cool air on it. Neglecting the radiation, heat transfer takes place by convection from outside and by con-

\section{

맘

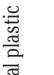


duction inside the PCS through the different materials. It is involved also the contact temperature of the bottom of the box:

$$
\rho \cdot C_{p} \cdot \frac{\partial T}{\partial t}=\nabla(k \nabla T)+Q
$$

where $\rho$ is the density, $C_{p}$ is the specific heat and $\mathrm{k}$ is the thermal conductivity of the different material, $Q$ is the heat sourced from the respiration rate, $T$ is temperature and $t$ is time:

$$
-\vec{n} \cdot(k \vec{\nabla} T)=h \cdot A \cdot\left(T_{e x t}-T\right)
$$

where the subscript $e x t$ is external, $h$ is the convective heat transfer coefficient, $\vec{n}$ is the normal vector on the boundary and $A$ is the area where there is convective heat transfer.

The heat flux due to the respiration of the berries was evaluated by means of correlation between the heat of respiration and the experimental temperature inside the blueberries mass and added to the other heat flux. Heat transfer coefficient was estimated with the relationship [correlation of McAdams (1954)] between the adimensional numbers of Nusselt and Rayleigh and were 9.4 and $10.2 \mathrm{~W} /\left(\mathrm{m}^{2} \mathrm{~K}\right)$ for horizontal $\left(\mathrm{Nu}=0.54 \mathrm{Ra}^{1 / 4}\right)$ and vertical $\left(\mathrm{Nu}=0.59 \mathrm{Ra}^{1 / 4}\right)$ walls respectively.

A 3D symmetrical model of the PCS filled with a $5 \mathrm{~cm}$ height slab with apparent thermal characteristics obtained from a weighted mean of air and fruit. Only a quarter of the whole geometry was drawn. The mesh is automatically created with a normal refinement and it is formed by 14398 tetrahedral elements. The model was focused on the thawing time of ice slab and on the temperature in the warmer point inside the blueberries mass (in the middle). Table 2 reports the thermo-physical properties of each material and Table 3 shows the initial temperature and input parameters used in the model.

Percentage of blueberries in mixed slab is fixed in $75 \%$ of blueberries and $25 \%$ of air, experimentally determined. Thermal conductivity was calculated following Maxwell-Eucken model (Sahin and Sumnu, 2006 ) with blueberries as continuous phase and air as dispersed phase. Its value was $0.370 \mathrm{~W} /(\mathrm{m} \mathrm{K})$.

To simulate the ice slab melting a modified specific heat was used (Marai et al., 2012):

$$
\mathrm{C}_{\mathrm{p}}=\mathrm{C}_{\mathrm{p} \text { ice }}+\mathrm{H}(\mathrm{T})\left(\mathrm{C}_{\mathrm{p} \mathrm{w}}-\mathrm{C}_{\mathrm{p} \text { ice }}\right)+\mathrm{G}(\mathrm{T}) \cdot \mathrm{lda}
$$

where the subscript $\mathrm{w}$ is water, lda is the latent heat of fusion, $\mathrm{H}$ is a smoothed step function of temperature from 0 to 1 and $\mathrm{G}$ is a Gaussian pulse centered in the fusion temperature. The pulse is necessary to simulate the latent heat of fusion (energy is absorbed while the temperature remains constant). The temperature range (defined by Gaussian pulse standard deviation) of the fusion and the smoothed step function is an approximation necessary because fusion at an exact temperature and discontinuous functions cannot be modelled numerically. Also $\rho$ and k of the water are modified density and thermal conductivity equations that consider the two phases of water (Marai et al., 2012):

$$
\rho=\rho_{\text {ice }}+\mathrm{H}(\mathrm{T}) \cdot\left(\rho_{\mathrm{w}}-\rho_{\text {ice }}\right)
$$

$\mathrm{k}=\mathrm{k}_{\text {ice }}+\mathrm{H}(\mathrm{T}) \cdot\left(\mathrm{k}_{\mathrm{w}}-\mathrm{k}_{\text {ice }}\right)$

\section{Results and discussion}

\section{Physical and chemical results}

Temperature profiles concerning sensors placed among fruits inside PCS and those among fruits inside traditional plastic boxes are shown in Figure 2.

Data are averaged on three repetitions and error bars show standard deviation every $15 \mathrm{~min}$. After $4 \mathrm{~h}$ and $45 \mathrm{~min}$ (corresponding to the time necessary for fruit harvest, transportation and placing of the samples into the storage cell) samples were placed together in storage cell at $0^{\circ} \mathrm{C}$.

The curve relative to the traditional boxes remains constant at $30^{\circ} \mathrm{C}$ for the entire trip time from field to storage. Regarding PCS the temperature inside the device placed among fruits has not dropped below $15^{\circ} \mathrm{C}$ temperature trace, after two hours, and decreased until $9.9 \pm 1.9^{\circ} \mathrm{C}$. The high value of standard deviation is due to the environmental temperature differences among sampling dates. The analysis of temperature profiles during transport with PCS shows how this device is not sufficiently fast in tearing down the blueberries field heat. Jackson et al. (1999) stated that a positive effect on the quality of blueberries is linked to a rapid decrease of their temperature soon after harvest, reaching $5^{\circ} \mathrm{C}$ in maximum $2 \mathrm{~h}$.

Table 1 represents the comparison among different storage times at $0^{\circ} \mathrm{C}$ for both blueberries cooled with PCS and for the control samples and comparison between the two transportation systems for each sampling date. The measured parameters are: weight loss, percentage of edible berries, texture (peak force and penetration energy), and chemical compounds (TSS and titratable acidity).

Results highlighted a physiological weight loss during storage time at $0^{\circ} \mathrm{C}$. The comparison between PCS and control showed a significant difference in all sampling dates. The carriage performed with PCS seems to have a positive effect in reducing the weight loss during the

Table 2. Thermo-physical properties of materials.

Symbol Blueberries Air Polystyrene Ice Water

\begin{tabular}{lcccccc}
$\begin{array}{l}\text { Density } \\
\left(\mathrm{kg} / \mathrm{m}^{3}\right)\end{array}$ & $\rho$ & 990 & 1.248 & 25 & 917 & 1000 \\
$\begin{array}{l}\text { Specific heat } \\
(\mathrm{J} / \mathrm{kg} \mathrm{K})\end{array}$ & $\mathrm{C}_{\mathrm{p}}$ & 3786 & 1013 & 1200 & 2260 & 4186 \\
$\begin{array}{l}\text { Thermal conductivity } \\
(\mathrm{W} / \mathrm{m} \mathrm{K})\end{array}$ & $\mathrm{k}$ & 0.539 & 0.024 & 0.033 & 2.208 & 0.6 \\
\hline
\end{tabular}

Table 3. Initial temperatures and input parameters.

\begin{tabular}{lcc}
\hline Parameters & Units & Value \\
Blueberries initial temperature & $\mathrm{K}$ & 302.25 \\
Polystyrene initial temperature & $\mathrm{K}$ & 295.15 \\
\hline Air initial temperature & $\mathrm{K}$ & 297.15 \\
Ice initial temperature & $\mathrm{K}$ & 253.15 \\
\hline Ice latent heat of fusion & $\mathrm{kJ} / \mathrm{kg}$ & 333.00 \\
Horizontal convective heat transfer coefficient & $\mathrm{W} / \mathrm{m}^{2} \mathrm{~K}$ & 9.40 \\
\hline Vertical convective heat transfer coefficient & $\mathrm{W} / \mathrm{m}^{2} \mathrm{~K}$ & 10.20 \\
Ambient temperature & $\mathrm{K}$ & 300.15 \\
\hline Ice fusion temperature & $\mathrm{K}$ & 273.15 \\
Percentage of blueberries in mixed slab & $\%$ & 75.00 \\
\hline
\end{tabular}


fruits storage. A decrease of the times is also detectable. As expected, the percentages of edible berries tend to decrease over time for both PCS and control, with a consistent trend. Regarding the comparison between the two transport systems, significant differences are noticeable starting from $\mathrm{T} 2$, with the only exception of $\mathrm{T} 3$. This is probably due to the high standard deviation for the blueberries transported using the control box, resulting in a negative significance test at this sampling time. The fruits carried with PCS showed better results beyond 23 days, preserving percentages of edible berries higher than those checked for the fruit carried in the traditional way.

No relevant trends are revealed for texture parameters among storage times and no significant differences are notable between blueberries collected with and without PCS among sampling dates. Concerning chemical analyses, TSS does not show significant changes during storage as regards the fruits carried with PCS. However, concerning the fruits transported without PCS it can be noticed a significant difference during the storage time. The use of the PCS seems to help a greater stability of the TSS parameter during storage. In any case, by comparing the two transportation methods, no significant differences occur regarding TSS, except at 63 days of storage. Almenar et al. (2008) studied shelf life of blueberries at different temperatures under different conditions. The authors show that the TSS remains relatively constant after 10 days of storage at $10^{\circ} \mathrm{C}$ and decreases slightly after 9 days of conservation at $23^{\circ} \mathrm{C}$.

Regarding the titratable acidity the trend over time tends to decrease slightly in the complex although are highlighted values in countertendency for certain sampling times. This behaviour during storage is found both for the fruits transported with and without the PCS. Results regarding weight loss, firmness, TSS, and titratable acidity show similar trends to those reported by Chiabrando and Giacalone (2011).

Overall, the comparison between fruits transported with PCS and control showed no significant differences for titratable acidity except in correspondence of the sampling dates in which the greater fluctuations of this parameter were present. Therefore, the use of the tested PCS for cooling shows a slight positive influence on the blueberries storage life only for few parameters (weight loss and percentage of edible berries). Instead, the use of the PCS showed no differences regarding fruit texture and chemical parameters compared to non-refrigerated transport. Computational numerical simulation of this PCS was modelled to find a solution for a storage life improvement and quality preservation during storage with cooling soon after harvest process. Experimental temperature data shown were used to validate the model. Computational simulation greatly developed in recent years, due to the powerful processor and cheapest memory banks, compatible with an integration of different aspects of the same problem in a single solution.

\section{Model results}

To verify the effect of the mesh size on the simulation solution, a grid independent study (Table 4) was carried out. Simulation was performed with three different mesh size $(6983,14398$ and 59434 elements) and results were compared to each other. Difference between ambient temperature and centre ice slab temperature at $15 \mathrm{~h}$, were considered for the relative error (\%change) computation (Equation 6):

$$
\% \text { change }=\frac{\mid \text { value }_{\text {coarse- }} \text { value }_{\text {fine }} \mid}{\text { value }_{\text {fine }}} \cdot 100
$$

where value $_{\text {coarse }}$ is the result from the model with less elements and value $_{\text {fine }}$ is the result of the model with more elements of each pair considered. The model realised with 14,398 elements, with the same performance compared to that with 59,434 elements, was chosen thanks to a shorter computing time. Figure 3 shows the temperature profiles of the blueberries in the apparent thermal properties slab model. The measured temperature among the blueberries presents a decreasing till about $285 \mathrm{~K}$.

The quality of the simulation is given by the mean relative error, which is defined as:

$$
e m(\%)=\frac{100}{n} \sum_{i=1}^{n}\left(\frac{\left|T_{\text {exp }}-T_{m o d}\right|}{T_{\text {exp }}}\right)_{i}
$$

where $n$ (121) is the number of experimental observations.

Table 4. Grid independence study.

\begin{tabular}{lccc} 
& Value $_{\text {coarse }}$ & Value $_{\text {fine }}$ & \%Change \\
Elements & 6983 & 14,398 & - \\
$\Delta \mathrm{T}(\mathrm{K})$ & 18.06 & 18.18 & 0.66 \\
\hline Elements & 14,398 & 59,434 & - \\
$\Delta \mathrm{T}(\mathrm{K})$ & 18.18 & 18.19 & 0.05 \\
\hline
\end{tabular}

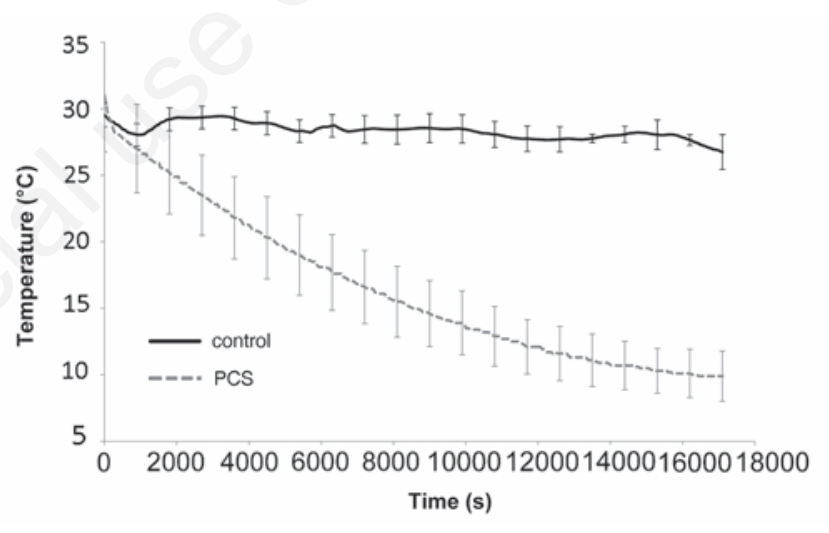

Figure 2. Temperature profile concerning sensors placed among fruits inside passive cooling system (PCS) compared with temperature profile of sensors among fruits inside traditional plastic boxes used as reference. Data are averaged on three repetitions, error bars show standard deviation every $15 \mathrm{~min}$. After $4 \mathrm{~h}$ and $45 \mathrm{~min}$ (end of trip from field to storage) samples were together placed in storage cell at $0^{\circ} \mathrm{C}$.

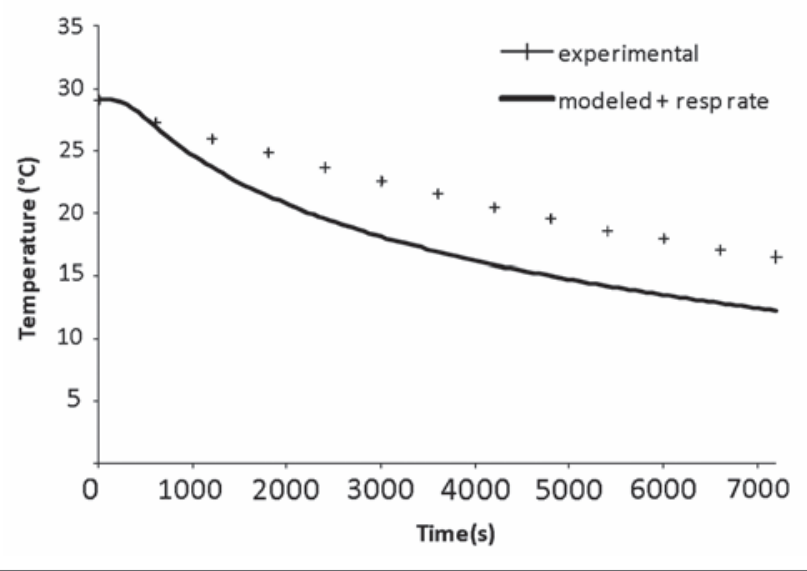

Figure 3. Simulated and experimental temperature data of blueberries layer (experimental points every $10 \mathrm{~min}$ ). 
The calculated $\mathrm{em}$ of the probe inside blueberries is $1.26 \%$. The $\mathrm{em}$ decreases to $0.98 \%$ if it is calculated on the whole simulation (till $15 \mathrm{~h}$ ). This behaviour could be partially due to the convection heat transfer inside the PCS, which was neglected in the simulation.

Slight differences along the modelled data and the experimental ones can be highlighted. In addition, blueberries are fruits naturally resistant to small thermal shock (for limited periods); for these reasons, highlighted differences are not worrying and the results can be considered overall encouraging.

The hypothesis of Jackson et al. (1999) that the improvement of the quality of blueberries is linked to a quickly decrease of their temperature (until $5^{\circ} \mathrm{C}$ in $2 \mathrm{~h}$ ) is the target of the present pack improvement work.

In order to improve the PCS performance further evaluations were performed. The variable that is possible to change in the PCS geometry is the walls thickness, which determines the amount of polystyrene for the construction of the pack.

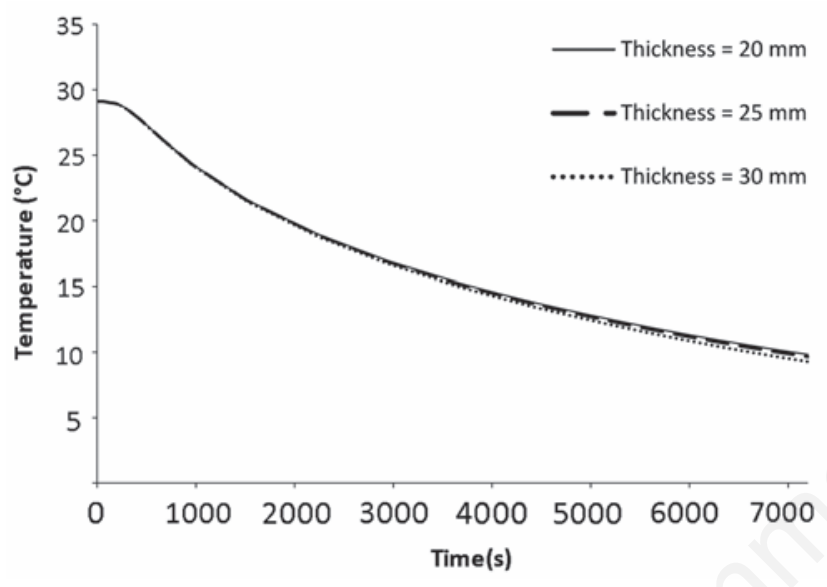

Figure 4. Simulation of temperature profile inside blueberries mass with different wall thickness from the experimental ones.

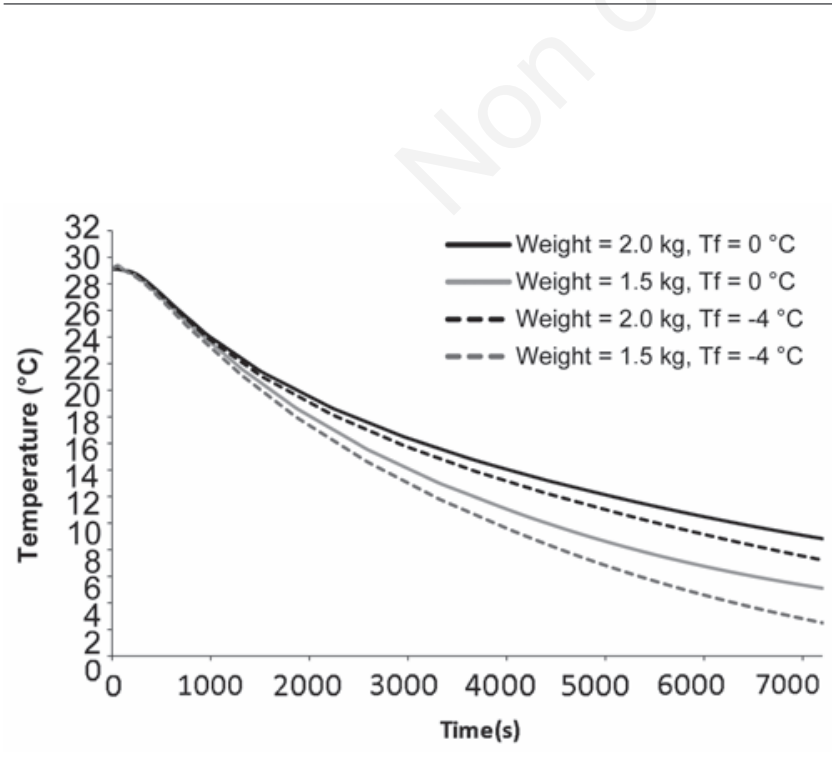

Figure 5. Simulation of temperature profile inside fruits with blueberries mass and melting temperature different from the experimental one.
Three different walls thicknesses were used for the optimisation of the geometry. The objective is the reduction of the temperature, so an increase of that parameter was tested. The chosen thicknesses were 20 (actual commercial PCS walls dimension), 25 and $30 \mathrm{~mm}$. Figure 4 shows the temperature trends of all the chosen values until $7200 \mathrm{~s}$ of simulation. It is possible to observe that there are no relevant differences (about $0.4 \%$ of decrease on the final temperature) among the tested parameters.

A diversification of the geometry parameters does not lead to an improvement of the pack performance due to the small temperature difference between inside and outside the box. The ice slab melting is mainly due to the blueberries cooling rather than to the heat transfer from outside. Moreover, the PCS optimisation is linked to the characteristics of the fruit inside the box.

Thermal properties of blueberries cannot be modified, so only the properties of the fluid in the charge could be changed. For example the use of a solution of salt in water could decrease the melting temperature and the latent heat of fusion. The best equilibrium is find with a material with the melting temperature of $-4^{\circ} \mathrm{C}$ and with the latent heat of fusion equal to $268 \mathrm{~kJ} \mathrm{~kg}^{-1}$. To further improve the performance of the system also a decrease of the quantity of stored blueberries inside the box was analysed. In particular a $25 \%$ decrease in blueberries weight. Figure 5 shows the temperature inside the blueberries mass of all the possible combination of the chosen values until $7200 \mathrm{~s}$ of simulation.

The best performance of the new PCS is obtained with a contemporaneous use of melting temperature at $-4^{\circ} \mathrm{C}$ and a decrease of the blueberries mass. The temperature obtained after $2 \mathrm{~h}$ in this case is about $2{ }^{\circ} \mathrm{C}$ in the middle of the blueberries mass, so the fruits placed in the bottom of the case could be frozen by the ice slab. Furthermore the use of a fluid other than water could cause contamination in the event of accidental contact between fluid and product. Such use is therefore not recommended as the risk of contamination exceeds the benefits on blueberries due to a faster cooling. The best solution to improve the performance of this PCS is to decrease the amount of blueberries coupled with a reduction of the container dimensions, and to keep water as changing phase fluid (a reduction of final temperature of about $50 \%$ ).

\section{Conclusions}

The results obtained from the use of PCS in the present configuration does not reach the optimal target (cooling until $5^{\circ} \mathrm{C}$ for $2 \mathrm{~h}$ ), even if the use of the device provides few advantages highlighted by the evaluation of the edible berries and the weight loss parameters. Chemical compounds and fruits texture parameters give comparable data for the two kind of transport packaging (PCS and non-refrigerated).

The future pattern of the PCS for the optimisation of the cooling soon after harvest operation will be designed to obtain a decrease to $5{ }^{\circ} \mathrm{C}$ within two hours from collection. Polystyrene thickness does not change the performance of the system (about $0.4 \%$ of decrease of temperature), with a temperature after $2 \mathrm{~h}$ of about $9^{\circ} \mathrm{C}$. The objective of $5^{\circ} \mathrm{C}$ in $2 \mathrm{~h}$ will be reached if the amount of blueberries inside the PCS will be reduced of $25 \%$, from the actual $2 \mathrm{~kg}$ to $1.5 \mathrm{~kg}$. So, it is possible to reduce the pack dimensions without changing the amount of ice to reach the target, resulting in no dramatic changes in handling and transportation costs. Each new package system will save about $600 \mathrm{~cm}^{3}$ of polystyrene. The simulation provided the useful information for the future optimisation of the PCS in order to further amplify the benefits on fruits along the cold chain. 


\section{References}

Almenar E., Samsudin H., Auras R., Harte B., Rubino M. 2008. Postharvest shelf life extension of blueberries using a biodegradable package. Food Chem. 110:120-7.

Anderson B.A., Sarkar A., Thompson J.F., Singh R.P. 2004. Commercial scale forced air cooling of strawberries. Trans. Am. Soc. Agric. Engine. 47:183-90.

Baird C.D., Gaffney J.J. 1976. A numerical procedure for calculating heat transfer in bulk loads of fruits or vegetables. ASHRAE Trans. 82:525-40.

Bartlett D. 1971. Vegetable review: cooling and storage. Comm. Grow. 3950:383-4.

Brazelton C. 2011. World blueberry acreage and production report. U.S. Highbush Blueberry Council. Available from: http://www.oregonblueberry.com/update/USHBC-report.pdf

Cantwell M. 2012. Properties and recommended conditions for storage of fresh fruits and vegetables. Postharvest UCDavis - University of California, Davis, CA, USA. Available from: Postharvest UCDavis http://postharvest.ucdavis.edu Accessed: Jun 20, 2012.

Castro L.R., Vigneault C., Cortez L.A.B. 2004. Effect of container opening area on air distribution during precooling of horticultural produce. Trans. Am. Soc. Agric. Engine. 47:2033-8.

Chiabrando V., Giacalone G. 2011. Shelf-life extension of highbush blueberry using 1-methylcyclopropene stored under air and controlled atmosphere. Food Chem. 126:1812-6.

Hoang M.L., Verboven P., Baelmans M., Nicolaï B.M. 2003. A continuum model for airflow, heat and mass transfer in bulk of chicory roots. Trans. Am. Soc. Agric. Engine. 46:1603-11.

Jackson E.D., Sanford K.A., Lawrence R.A., Mcrae K.B., Stark R. 1999. Lowbush blueberry quality changes in response to prepacking delays and holding temperatures. Postharv. Biol. Technol. 15:117-26.

Janick J. 1986. Horticultural science. 4th ed. Freeman WH, New York, NY, USA, pp 550-551.

Kader A.A. 2002. Postharvest technology of horticultural crops, 3rd ed.
Division of Agriculture and Natural Resources - University of California, Oakland, CA, USA.

Marai S.V., Ferrari E., Civelli R. 2012. Postharvest cold chain optimisation of little fruits. COMSOL Conference 2012, Milan, Italy, presentation and proceeding on CD-ROM.

McAdams W.H. 1954. Heat transmission, 3rd ed. McGraw-Hill, Columbus, USA.

Mitcham E.J., Crisosto C.H., Kader A.A. 2012. Bayas (Berries): zarzamora (mora), arándano azul, arándano rojo, frambuesa. Recomendaciones para mantener la calidad postcosecha. Dept. of Pomology, Postharvest UCDavis - University of California, Davis, CA, USA. Available from: http://postharvest.ucdavis.edu Accessed: Jun 15, 2012.

Moggia C. 1991. Aspectos de cosecha y poscosecha de arándanos. Seminario Internacional: Arándano. Agronomy School, University of Talca, Chile, pp 80.

Nowak J., Mynett K. 1985. The effects of growth regulators on the postharvest characteristics of cut lilium 'prima' inflorescences. Acta Hort. 167:109-16.

Paniagua A.C., East A.R., Heyes J.A. 2014. Interaction of temperature control deficiencies and atmosphere conditions during blueberry storage on quality outcomes. Postharv. Biol. Technol. 87:133-9.

Rudnucki R.M., Nowak J., Goszczynska D.M. 1991. Cold storage and transportation conditions for cut flowers cuttings and potted plants. Acta Hort. 298:225-30.

Ryall A.L., Pentzer W.T. 1982. Handling, transportation and storage of fruits and vegetables. AVI Pub.Co., Westport, CT, USA.

Sahin S., Sumnu S.G. 2006. Physical properties of foods. Springer Science, New York, NY, USA.

Sinelli N., Spinardi A., Di Egidio V., Mignani I., Casiraghi E. 2008. Evaluation of quality and nutraceutical content in blueberries (Vaccinium corymbosum L.) by near and mid-infrared spectroscopy. Postharv. Biol. Technol. 50:31-6.

Thompson J.F., Mitchell G.F., Rumsey T.R., Kasmire R.F., Crisosto C.H. 2008. Commercial cooling of fruits, vegetables and flowers. UCANR Publications, Oakland, CA, USA. 